\title{
Synthesis, Antitubercular and Leishmanicidal Evaluation of Resveratrol Analogues
}

\author{
Elaine S. Coimbra, ${ }^{a}$ Juliana A. Santos, ${ }^{b}$ Larissa L. Lima, ${ }^{b}$ Patrícia A. Machado, ${ }^{a}$ \\ Débora L. Campos, ${ }^{c}$ Fernando R. Pavan ${ }^{c}$ and Adilson D. Silva ${ }^{*, b}$
}

${ }^{a}$ Departamento de Parasitologia, Microbiologia e Imunologia, ICB and ${ }^{b}$ Departamento de Química, ICE, Universidade Federal de Juiz de Fora, 36036-900 Juiz de Fora-MG, Brazil

${ }^{c}$ Departamento de Ciências Biológicas, FCF, Universidade Estadual Paulista Júlio de Mesquita Filho, 14801-902 Araraquara-SP, Brazil

\begin{abstract}
In this paper we continue our efforts in the search for new Schiff bases as resveratrol analogues as promising antitubercular and antileishmanial agents. Compounds were evaluated in vitro against Mycobacterium tuberculosis and Leishmania species. Compounds showed varying activity against promastigotes of all Leishmania species tested (concentration leading to reduction of $50 \%$ of parasite growth- $\mathrm{IC}_{50}$ values ranging from 1.60 to $15.53 \mu \mathrm{g} \mathrm{mL}-1$ ). Majority of compounds exhibited good results against Leishmania species with $\mathrm{IC}_{50}$ values below $10.00 \mu \mathrm{g} \mathrm{mL} \mathrm{L}^{-1}$, with no cytotoxicity against macrophages. One of the analogues showed the best activity against amastigotes of L. amazonensis $\left(\mathrm{IC}_{50}=5.73 \mu \mathrm{g} \mathrm{mL} \mathrm{mL}^{-1}\right)$. Furthermore, the compounds showed comparable or better effect than drugs commonly used in tuberculosis treatment such as Cycloserine ${ }^{\circledR}$. The analogue that was the most active for $M$. tuberculosis had minimal inhibitory concentration $\mathrm{MIC}_{90}=0.78 \mu \mathrm{g} \mathrm{mL}^{-1}$. The in vitro cytotoxicity on Vero cells $\left(\mathrm{CC}_{50}\right)$, as well as the selectivity index $\left(\mathrm{SI}=\mathrm{CC}_{50} / \mathrm{MIC}\right)$ were also evaluated, and showed that the synthesized analogues are not cytotoxic.
\end{abstract}

Keywords: resveratrol analogue, antitubercular evaluation, leishmanicidal evaluation, Schiff base, imine

\section{Introduction}

Infectious diseases are caused by several pathogenic microorganisms and remain as a major public health concern in most of the developing countries. Tuberculosis (TB) is an infectious bacterial disease caused by Mycobacterium tuberculosis (MTB) and recent report showed that 6 million new cases of TB with 1.5 million deaths were reported to WHO. ${ }^{1,2}$ Emergence of multidrugresistant $\mathrm{TB}$, extensively drug-resistant $\mathrm{TB}$, and most recently, strains that are resistant to all antituberculosis drugs justify the search for new therapies for this disease. ${ }^{3}$ Leishmaniasis is caused by parasitic protozoa of the genus Leishmania and included in the list of Neglected Tropical Diseases by the World Health Organization (WHO). ${ }^{4}$ This disease is endemic in 98 countries, with approximately two million new cases worldwide. ${ }^{4,5}$ Conventional therapy with pentavalent antimonials exhibit high toxicity and various side effects have been reported.

*e-mail: david.silva@ufj.edu.br
In order to synthesize original molecules exhibiting anti-MTB and anti-Leishmania activities, our research group previously reported promising results in new Schiff bases as resveratrol (trans-3,5,4'-trihydroxystilbene) (Figure 1) analogues.

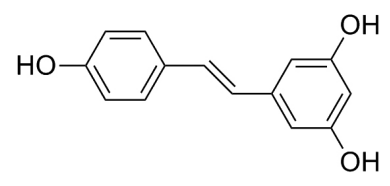

Figure 1. Chemical structure of trans-resveratrol.

Resveratrol is a natural polyphenolic phytochemical found in redwine, grapes, peanuts, and some berries. It is biosynthesized in response to pathogenic attack or stress conditions. ${ }^{6,7}$ This stilbene has been the subject of numerous research investigations because of the wide variety of biological activity associated with this compound. Resveratrol have an important role in the prevention and progressive reduction of diseases and pathological processes such as inflammation,,$^{8-10}$ cancer $^{11,12}$ and heart diseases. ${ }^{8,13,14}$ Additional properties, such as antioxidant, ${ }^{8,15}$ 
neuroprotective, ${ }^{16,17}$ free radicals scavenger, and even fighting Alzheimer's disease ${ }^{18,19}$ have been also attributed to resveratrol.

Our research group has been developing and reporting the use of classic bioisosterism in building potentially active analogues of resveratrol. ${ }^{20}$ Modification is made by substitution of the central $\mathrm{C}=\mathrm{C}$ linkage with a $\mathrm{C}=\mathrm{N}$ double bond, originating calls Schiff bases (Figure 2).
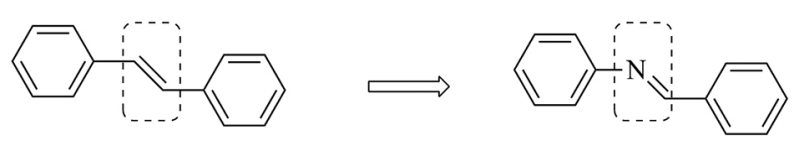

Figure 2. Classic bioisosterism in the stilbenoid nucleus.

The first report of activity against in vitro MTB infection in Schiff bases was reported recently by our research group. ${ }^{21}$ Results show that bioisosters compounds synthesized can be considered as promising anti-MTB agents, since it showed MIC in the range of $15.6 \mu \mathrm{g} \mathrm{mL}^{-1}$. Also, these bioisosters have reported promising leishmanicidal activity. ${ }^{22}$ As a continuation of our efforts to synthesize new Schiff bases as resveratrol analogues, here we describe the synthesis of six positional isomers (regioisomers) 1-6, which were prepared using classical methods of imine formation as previously reported. ${ }^{23-27}$ In this manuscript, for the first time, these compounds were assayed against MTB and Leishmania species.

\section{Experimental}

\section{Chemistry}

\section{General methods}

Melting points were recorded in a Mel-Temp apparatus and are uncorrected. Infrared spectra were recorded on a Schimadzu 8400 series FTIR (Fourier transform infrared) instrument. ${ }^{1} \mathrm{H}$ NMR (nuclear magnetic resonance) spectra were recorded on a Bruker AC-300 and 500 spectrometers at 300.13 and $500.13 \mathrm{MHz}$ and ${ }^{13} \mathrm{C}$ NMR spectra were recorded on a Bruker AC-300 at $75 \mathrm{MHz}$. Chemical shifts are given in parts per million relative to tetramethylsilane. All reagents used were analytical reagent grade.

General procedure for the preparation of resveratrol analogs

Schiff bases as resveratrol analogues 1-6 were prepared by condensation of 2-hydroxyaniline with the equimolar amount of aromatic aldehydes in ethanol as shown in Figure 3. Classical method of Schiff bases formation was used and all products were obtained as solids after filtered, washed with ethanol and dried in an oven. Reaction time averaged 10 minutes to 168 hours and all compounds were obtained as colored solids in moderate yields (50-90\%). Spectral data of six analogues are shown in Table 1 and are in accordance with those described in the literature for these compounds..$^{23-27}$

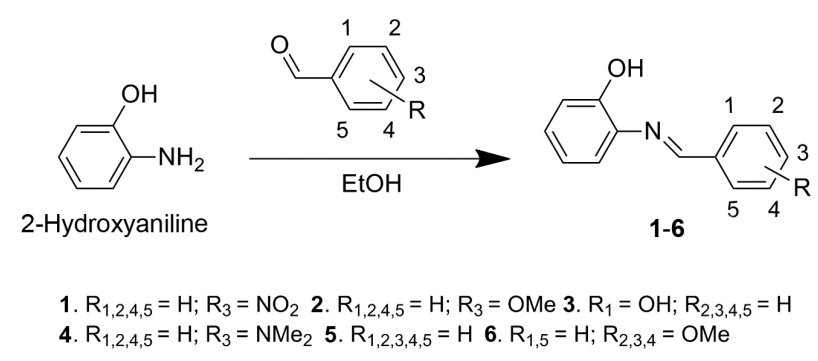

Figure 3. Scheme of the synthetic pathway for resveratrol analogues 1-6.

\section{Biological assay}

Determination of minimal inhibitory concentration $\left(\mathrm{MIC}_{90}\right)$

Anti-MTB activity of the compounds was determined using the Resazurin Microtiter Assay (REMA) method according to Palomino et al. ${ }^{28}$ Stock solutions of the tested compounds were prepared in dimethylsulfoxide (DMSO), then diluted in Middlebrook 7H9 broth (Difco, Detroit, MI, USA) supplemented with oleic acid, albumin, dextrose and catalase (OADC enrichment-BBL/Becton-Dickinson, Detroit, MI, USA) in Precision XS automation (Biotek ${ }^{\mathrm{tm}}$ ) to obtain a final drug concentration range of $0.09-25 \mu \mathrm{gL}^{-1}$.

Table 1. Spectral data of resveratrol analogues

\begin{tabular}{lccccc}
\hline Compound & $\delta \mathrm{C} \underline{\mathrm{H}}=\mathrm{N}$ & $\delta \underline{\mathrm{C}}=\mathrm{N}$ & $\overline{\mathrm{v}} \mathrm{C}=\mathrm{N}$ & Melting point $/{ }^{\circ} \mathrm{C}$ & Yield $/ \%$ \\
\hline $\mathbf{1}$ & 8.90 & 157.18 & 1625.8 & $160.0-161.0$ & 78.0 \\
$\mathbf{2}$ & 8.62 & 158.46 & 1622.0 & $90.1-92.0$ & 66.0 \\
$\mathbf{3}$ & 8.96 & 160.77 & 1631.6 & $149.0-150.3$ & 90.0 \\
$\mathbf{4}$ & 8.50 & 158.84 & 1614.3 & $118.0-119.0$ & 50.0 \\
$\mathbf{5}$ & 8.69 & 159.73 & 1625.8 & $90.8-91.5$ & 83.0 \\
$\mathbf{6}$ & 8.63 & 158.87 & 1623.9 & $118.7-119.6$ & 72.0 \\
\hline
\end{tabular}

The NMR experiments were performed at $300 \mathrm{MHz}$ for ${ }^{1} \mathrm{H}$ and $75 \mathrm{MHz}$ for ${ }^{13} \mathrm{C}$ in dimethyl sulfoxide (DMSO- $\left.d_{6}\right)(\mathrm{ppm})$ and IR experiments were performed at $\mathrm{KBr}$ support $\left(\mathrm{cm}^{-1}\right)$. 
A suspension of the M. tuberculosis H37Rv ATCC 27294 was cultured in Middlebrook 7H9 broth supplemented with OADC and $0.05 \%$ Tween 80 . Culture was frozen at $-80{ }^{\circ} \mathrm{C}$ in aliquots. After two days, the colony-forming unit (CFU) $\mathrm{mL}^{-1}$ of the aliquot was determined. Concentration was adjusted to $5 \times 10^{5} \mathrm{CFU} \mathrm{mL} \mathrm{m}^{-1}$, and $100 \mu \mathrm{L}$ of the inoculums was added to each well of a 96-well micro plate together with $100 \mu \mathrm{L}$ of the compounds. Samples were set up in triplicate. The plate was incubated for 7 days at $37{ }^{\circ} \mathrm{C}$. After $24 \mathrm{~h}$, $30 \mu \mathrm{L} 0.01 \%$ resazurin (solubilized in water) was added. Fluorescence of the wells was read after 24 hours using a Cytation 3 (Biotek $\left.{ }^{\mathrm{tm}}\right)$ reader using excitation and emission filters at wavelengths of 530 and $590 \mathrm{~nm}$, respectively. The $\mathrm{MIC}_{90}$ was defined as the lowest concentration resulting in $90 \%$ inhibition of growth of MTB. Antitubercular activity of resveratrol (Resveratrol Extract 8\%, distributed by Galena ${ }^{\circledR}$, Brazil) was also evaluated, since the synthetic compounds are described as analogues of this polyphenol.

\section{In vitro cytotoxic activity against mammalian cells}

Cytotoxicity of the compounds diluted in DMSO was measured on normal epithelial cells (VeroATCC CCL-81) and on murine peritoneal macrophages. Cytotoxicity assay on Vero cells was performed as described by Pavan et al..$^{29}$ Cells were incubated at $37{ }^{\circ} \mathrm{C}$ with $5 \%$ $\mathrm{CO}_{2}$ on plates with a surface area of $12.50 \mathrm{~cm}^{2}$ in $10 \mathrm{~mL}$ DMEM (Dulbecco's Modified Eagle Medium) (Vitrocell ${ }^{\circledR}$, Campinas, SP, Brazil) supplemented with $10 \%$ fetal bovine serum (FBS), gentamicin sulfate $\left(50 \mathrm{mg} \mathrm{L}^{-1}\right)$ and amphotericin $\mathrm{B}\left(2 \mathrm{mg} \mathrm{L}^{-1}\right)$. This technique consists of collecting the cells using a solution of trypsin/EDTAethylenediamine tetraacetic acid (Vitrocell ${ }^{\circledR}$ ), centrifuging (252 $\mathrm{g}$ for $5 \mathrm{~min}$ ), counting the number of cells in a Neubauer chamber and then adjusting the concentration to $3.4 \times 10^{5}$ cells $\mathrm{mL}^{-1}$ in DMEM. ${ }^{30}$ Next, $200 \mu \mathrm{L}$ suspension was deposited into each well of a 96-well microplate obtaining a cell concentration of $6.8 \times 10^{4}$ cells well $^{-1}$ and incubated at $37{ }^{\circ} \mathrm{C}$ in an atmosphere of $5 \% \mathrm{CO}_{2}$ for 24 hours to allow the cells to attach to the plate. Dilutions of the test compounds were prepared to obtain concentrations from 500 to $1.95 \mu \mathrm{g} \mathrm{mL}^{-1}$. Dilutions were added to the cells after the removal of the medium and any cells that did not adhere, and incubated again for 24 hours. Cytotoxicity of the compounds was determined by adding $30 \mu \mathrm{L}$ developer of resazurin and read after 6 hours incubation. Reading was performed in a microplate Cytation 3 (Biotek ${ }^{\mathrm{tm}}$ ) reader using excitation and emission filters at wavelengths of 530 and $590 \mathrm{~nm}$, respectively.

Cytotoxicity assays on murine peritoneal macrophages was performed according to Machado et al. ${ }^{31}$ Briefly, inflammatory macrophages were obtained from BALB/c mice previously inoculated intraperitoneally with $2 \mathrm{~mL}$ of $3 \%$ thioglycollate medium (Sigma Chemical Co., St. Louis, MO, USA). Viability was determined by the colorimetric 3-(4,5-dimethylthiazol-2-yl)-2,5-diphenyltetrazolium bromide (MTT-Sigma Chemical Co., St. Louis, MO, USA) method based on tetrazolium salt reduction by mitochondrial dehydrogenases. Cells were plated in 96-well culture plates $\left(2 \times 10^{6}\right.$ cells $\left.\mathrm{mL}^{-1}\right)$, in RPMI 1640 medium supplemented with $10 \%$ FBS. Adherent macrophages were incubated with the compounds in several concentrations

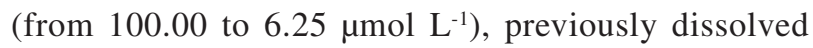
in DMSO, for 72 hours, at $33^{\circ} \mathrm{C}$. Then, the cells were incubated with $10 \mu \mathrm{L}$ of MTT solution of $5 \mathrm{mg} \mathrm{mL}^{-1}$ during two hours at $37{ }^{\circ} \mathrm{C}$ in $5 \% \mathrm{CO}_{2}$. Reaction was stopped by adding $100 \mu \mathrm{L}$ of isopropanol acid and the absorbance was measured at $570 \mathrm{~nm}$ (Multiskan MS microplate reader, LabSystemsOy, Helsink, Finland). Viability of the macrophages was determined with the MTT assay and was also confirmed by comparing the morphology of the control group by light microscopy. Controls with DMSO and without drugs were also performed. All tests were performed in duplicate. All protocols were approved by the Ethical Committee for Animal Research of the Federal University of Juiz de Fora (054/2013-CEEA).

Amounts of compounds which led to the reduction of $50 \%$ on cell viability $\left(\mathrm{CC}_{50}\right)$ were used as a parameter for cytotoxicity. $\mathrm{CC}_{50}$ values were obtained from three independent experiments performed in duplicate and $\mathrm{CC}_{50}$ values with their $95 \%$ confidence limits were calculated by using GraFit Version 5 software (Erithacus Software Ltd., Horley, UK).

\section{Selectivity index (SI)}

The SI of each compound was determined as the ratio of $\mathrm{CC}_{50}$ to $\mathrm{MIC}_{90}$. According to Orme et al. ${ }^{32}$ candidates for new drugs must have a selectivity index equal to or higher than 10 .

\section{In vitro leishmanicidal activity}

Promastigote assay: promastigote forms of three species of Leishmania such as L. amazonensis (IFLA/ Br/67/PH8), L. braziliensis (MHOM/Br/75/M2903) and L. major (MRHO/SU/59/P) were used. Anti-leishmanial activity was performed by using the colorimetric method MTT (Sigma-Aldrich, St. Louis, MO, USA), as previously described. ${ }^{33}$ Promastigotes of L. amazonensis were cultured in Warren's medium (brain heart infusion plus hemin and folic acid) and promastigotes of L. braziliensis and L. major were maintained in BHI medium plus $L$-glutamine and male urine sterile, both supplemented with $10 \%$ FBS at $25{ }^{\circ} \mathrm{C}$. Screening was performed in 96-well microtiter 
plates maintained at $25^{\circ} \mathrm{C}$. Promastigotes from a logarithmic phase culture were suspended to yield $2 \times 10^{6}$ or $3 \times 10^{6}$ cells $\mathrm{mL}^{-1}$ after Neubauer chamber counting. Parasites were exposed to the compounds (25.00 to $1.56 \mu \mathrm{g} \mathrm{mL}^{-1}$ ), previously dissolved in DMSO, for 72 hours. Controls with DMSO and without drugs were performed. All tests were performed in duplicate. For data analysis: concentration leading to reduction of $50 \%$ of parasite growth $\left(\mathrm{IC}_{50}\right.$ values) were obtained from at least three independent experiments performed in triplicate, by using GraFit Version 5 software (Erithacus Software Ltd., Horley, UK). Miltefosine (Cayman Chemical Company, Michigan, USA) was used as the reference standard. Leishmanicidal activity of resveratrol (Resveratrol Extract 8\%, distributed by Galena ${ }^{\circledR}$, Brazil) was also evaluated.

Amastigote assay: for antiamastigote activity, macrophages were obtained from BALB/c mice previously inoculated with $3 \%$ thioglycolate medium (Sigma Chemical Co.; St. Louis, MO, USA). Peritoneal macrophages were plated in a 24-well plate in RPMI 1640 medium supplemented with $10 \%$ inactivated FBS and allowed to adhere for $24 \mathrm{~h}$ at $33{ }^{\circ} \mathrm{C}$ in $5 \% \mathrm{CO}_{2}$. Adherent macrophages were infected with L. amazonensis promastigotes (MHOM/ $\mathrm{Br} / 75 / \mathrm{Josefa})$, transfected with green protein fluorescent (GFP), in the stationary growth phase, using a ratio of 1:20 at $33{ }^{\circ} \mathrm{C}$ for 4 hours. ${ }^{34,35}$ Non internalized promastigotes were eliminated and the test compounds were added in several concentrations. After 72 hours of incubation with the compounds, the cells were lysed with distilled water and transferred to black microplates. Relative fluorescence units (RFUs) were measured using a spectrofluorometer (FLx800, BioTek Instruments, Inc., Winooski, VT, USA), at excitation and emission wavelengths of 485 and $528 \mathrm{~nm}$, respectively. The $\mathrm{IC}_{50}$ values were obtained from three independent experiments, using Probit program. Miltefosine (Cayman Chemical Company, Michigan, USA) were used as reference substance.

\section{Results and Discussion}

Trying to reach a new derivative of resveratrol with better activity against MTB and Leishmania species, six compounds were synthesized in order to compare their biological profile based on the isomer position previously reported. $^{21}$

\section{Antitubercular activity}

In vitro antiproliferative activity of the compounds 1-6 against MTB H37Rv (ATCC 27294) ( MIC $_{90}$ ), cytotoxicity $\left(\mathrm{CC}_{50}\right)$ on Vero cells and SI can be seen in the Table 2.
First observation is that all synthesized analogues were more active against MTB and less cytotoxic on Vero cells than resveratrol. Analogues $\mathbf{2}$ and $\mathbf{3}$ showed similar $\mathrm{MIC}_{90}$ with values of $1.56 \mu \mathrm{g} \mathrm{mL} \mathrm{mL}^{-1}$ (or 6.86 and $7.32 \mu \mathrm{M}$, respectively) and low toxicity (SI $=113$ and 40 , respectively) which characterizes these Schiff bases with high selectivity toxicity. Analogue $\mathbf{4}$ presents the lowest MIC value of the series $\left(0.78 \mu \mathrm{g} \mathrm{mL}^{-1}\right.$ or $\left.3.24 \mu \mathrm{M}\right)$, whereas analogue $\mathbf{5}$ presents the highest $\mathrm{IC}_{50}$. However, when we are seeking for a "magic bullet" we have to choose the compound with the best selectivity toxicity and in our case is the compound 2. Among the compounds, only the analogue $6\left(\mathrm{MIC}_{90}>25\right)$ did not show activity against MTB. A classification of the resveratrol analogues in agreement with the increasing potential as anti-MTB agent, considering the SI values referred for Vero cells is $\mathbf{1}<\mathbf{3}<\mathbf{5}<\mathbf{4}<\mathbf{2}$. It is interesting to note that most resveratrol analogues here tested $\left(\mathrm{IC}_{50}\right.$ ranging from 0.78 to $6.25 \mu \mathrm{g} \mathrm{mL}^{-1}$ ) (Table 2) were more effective against MTB than aza-stilbene derivatives $\left(\mathrm{IC}_{50}\right.$ ranging from 15.60 to $31.25 \mu \mathrm{g} \mathrm{mL} \mathrm{m}^{-1}$ ) previously reported by our research group. ${ }^{21}$

It is important to highlight the values of $\mathrm{MIC}_{90}$ found for the synthesized analogs 1-5 are better than "first-line" drug as pyrazinamide ( $\mathrm{MIC}=20-50 \mu \mathrm{gL}^{-1}$ ) and "second-line" as Cycloserine ${ }^{\circledast}\left(\mathrm{MIC}=12.5-50.0 \mu \mathrm{g} \mathrm{mL}^{-1}\right)$, both currently used in TB therapy. ${ }^{36}$

\section{Leishmanicidal activity}

Leishmaniasis is a disease caused by several Leishmania species resulting in a variety of clinical manifestations that range from the cutaneous form to the fatal visceral leishmaniasis, depending on complex interactions between the parasite and the host immune response. ${ }^{37}$ In this work, all resveratrol analogues were tested against promastigote forms of L. amazonensis, L. braziliensis and L. major and against amastigote forms of $L$. amazonensis. These Leishmania species cited are related to cutaneous manifestations; L. amazonensis and L. braziliensis are reported in Latin America and L. major is found in several countries of the Old World. ${ }^{4}$ Table 3 shows the leishmanicidal activity of the resveratrol analogues.

Compounds showed variations in antipromastigote activity against all Leishmania species tested, with the $\mathrm{IC}_{50}$ values ranging from 1.60 to $7.84 \mu \mathrm{g} \mathrm{mL} \mathrm{m}^{-1}$. Several compounds showed a strong activity, with $\mathrm{IC}_{50}<10.00 \mu \mathrm{g} \mathrm{mL}-1$. Analogue 2 showed the best $\mathrm{IC}_{50}$ value $\left(1.60 \mu \mathrm{gL}^{-1}\right)$ against promastigotes of $L$. braziliensis and the analogue 3 showed activity against all Leishmania species tested with $\mathrm{IC}_{50}$ values ranging from 2.50 to $7.84 \mu \mathrm{gL}^{-1}$. 
Table 2. In vitro antiproliferative activity of the compounds 1-6 against MTB H37Rv (ATCC 27294) (MIC 90 ), cytotoxicity $\left(\mathrm{CC}_{50}\right)$ on Vero cells, selectivity index (SI)

\begin{tabular}{|c|c|c|c|c|c|c|}
\hline Analogue & Chemical structure & $\begin{array}{c}\mathrm{MIC}_{90} / \\
\left(\mu \mathrm{gL} \mathrm{m}^{-1}\right)\end{array}$ & $\begin{array}{c}\mathrm{CC}_{50} / \\
\left(\mu \mathrm{g} \mathrm{mL}^{-1}\right)\end{array}$ & $\begin{array}{c}\mathrm{MIC}_{90} / \\
\mu \mathrm{M}\end{array}$ & $\begin{array}{c}\mathrm{CC}_{50} / \\
\mu \mathrm{M}\end{array}$ & SI \\
\hline 1 & & 3.13 & 96.50 & 12.93 & 398.64 & 31 \\
\hline 2 & & 1.56 & 176.0 & 6.86 & 775.02 & 113 \\
\hline 3 & & 1.56 & 62.80 & 7.32 & 294.72 & 40 \\
\hline 4 & & 0.78 & 45.60 & 3.24 & 189.89 & 59 \\
\hline 5 & & 6.25 & 352.60 & 31.71 & 1789.12 & 56 \\
\hline 6 & & $>25$ & 78.70 & $>87.07$ & 274.10 & $\leq 3$ \\
\hline Resveratrol & & $>25$ & 22.50 & 109.53 & 98.58 & - \\
\hline
\end{tabular}

The $\mathrm{MIC}_{90}$ and $\mathrm{CC}_{50}$ values for anti MTB and cytotoxicity on Vero, respectively, were expressed in $\mu \mathrm{g} \mathrm{mL}^{-1}$ and the $\mu \mathrm{M}$ equivalent.

Similar to the observed against MTB, the majority of the synthesized compounds were more active than resveratrol against Leishmania sp. promastigotes (Table 3). Furthermore, several analogues showed best leishmanicidal activity than miltefosine (except L. major), used as control drug. Miltefosine had been considered as the first oral drug used in visceral leishmaniasis treatment in India Subcontinent. ${ }^{38}$

Leishmania sp. is an obligate intracellular parasite and the macrophages are considered as the main host cell. With this in mind, we assayed the compounds on murine peritoneal macrophages since these cells have been considered as the most accurate model for intracellular assays. ${ }^{39}$ None of the compounds showed cytotoxicity against murine peritoneal macrophages at the maximum concentration tested at $100.0 \mu \mathrm{M}$ or the equivalent $25.0 \mu \mathrm{g} \mathrm{mL}^{-1}$ (data not shown). Due to the effective activity of the compounds against Leishmania species promastigotes and low cytotoxicity against murine 
Table 3. Leishmanicidal activity of the resveratrol analogues

\begin{tabular}{|c|c|c|c|c|c|}
\hline \multirow[t]{2}{*}{ Analogue } & \multirow[t]{2}{*}{ Chemical structure } & \multicolumn{3}{|c|}{$\begin{array}{l}\text { Promastigote } \\
\mathrm{IC}_{50} /\left(\mu \mathrm{g} \mathrm{mL}{ }^{-1}\right)\end{array}$} & \multirow{2}{*}{$\begin{array}{c}\text { Amastigote } \\
\left.\mathrm{IC}_{50} /(\mu \mathrm{g} \mathrm{mL})^{-1}\right) \\
\text { L. amazonensis }\end{array}$} \\
\hline & & L. amazonensis & L. braziliensis & L. major & \\
\hline 1 & & $>25$ & 6.73 & $>25$ & $>12$ \\
\hline 2 & & 3.81 & 1.60 & $>25$ & 9.26 \\
\hline 3 & & 6.46 & 2.50 & 7.84 & 8.54 \\
\hline 4 & & 4.74 & 3.15 & $>25$ & 9.07 \\
\hline 5 & & 5.29 & 2.57 & $>25$ & 5.93 \\
\hline 6 & & 4.17 & 4.95 & $>25$ & 5.73 \\
\hline Resveratrol & & $>25$ & $>25$ & $>25$ & $>25$ \\
\hline Miltefosine & & 856 & 1144 & 815 & 220 \\
\hline
\end{tabular}

Reference drug for leishmanicidal assays. These data represent the average of at least three independent experiments performed in duplicate.

macrophages, we decided to assay the resveratrol analogues against the intramacrophage parasite forms. Classic microscopic method for efficacy against intracellular amastigotes of Leishmania is labor intensive, cannot be automated and subject to observer variation. ${ }^{40}$ This way, in this work we used L. amazonensis promastigotes transfected with GFP for the antiamastigotes assay. All resveratrol analogues were tested against amastigote forms of L. amazonensis and the results can be seen at Table 3. Compounds 2-6 were very effective with the $\mathrm{IC}_{50}$ values below $10 \mu \mathrm{g} \mathrm{mL}^{-1}\left(\mathrm{IC}_{50}\right.$ values ranging from 5.73 to $\left.9.26 \mu \mathrm{g} \mathrm{mL}^{-1}\right)$. Compounds $\mathbf{5}$ and $\mathbf{6}$ were the most effective

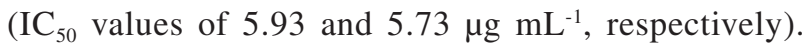
Only the compound $\mathbf{1}$ did not show activity against these intracellular forms at the maximum concentration tested (12.00 $\mu \mathrm{g} \mathrm{mL}^{-1}$, equivalent to $\left.50 \mu \mathrm{M}\right)$. 
Previous reports showed that resveratrol and some analogs (pterostilbene, piceatannol, polydatin and oxyresveratrol) are effective against $L$. amazonensis. ${ }^{41,42}$ According to these works, these compounds were active against promastigotes $\left(\mathrm{IC}_{50}\right.$ ranging from 17.7 to $95.5 \mu \mathrm{M})$ and intracellular amastigotes $\left(\mathrm{IC}_{50}\right.$ ranging from 29.0 to $42.0 \mu \mathrm{M}$ ). Our results showed that most of the analogues tested in this work were more effective on L. amazonensis and L. braziliensis promastigotes $\left(\mathrm{IC}_{50}\right.$ ranging from 1.60-6.73 $\mu \mathrm{g} \mathrm{mL} \mathrm{m}^{-1}$ or 7.04-30.31 $\left.\mu \mathrm{M}\right)$ (Table 3) than resveratrol, ${ }^{41}$ pterostilbene, piceatannol, polydatin and oxyresveratrol. ${ }^{42}$ Against amastigote forms of L. amazonensis, the compound $\mathbf{6}\left(\mathrm{IC}_{50}=5.73 \mu \mathrm{g} \mathrm{mL}^{-1}\right.$ or $19.95 \mu \mathrm{M})$ (Table 3) was also more effective than resveratrol and analogues. ${ }^{41,42}$ Similar to our results, resveratrol ${ }^{41}$ and analogues ${ }^{42}$ also did not present significant toxicity against mammalian cells.

\section{Structure activity relationship (SAR)}

\section{Antitubercular}

Arrangement in a decreasing order of MIC values increasing anti-MTB activity $(\mathbf{5}<\mathbf{1}<\mathbf{2}, \mathbf{3}<\mathbf{4})$ is an easy way to observe how the activity changes with the modifications of the R groups, that is, with the nature of the substituent group in the portion of the original aldehyde. Analogue 4 was the most active $\left(\mathrm{MIC}_{90}=0.78 \mu \mathrm{g} \mathrm{mL}^{-1}\right)$ indicating that the presence of the substituent $\mathrm{N}\left(\mathrm{CH}_{3}\right)_{2}$, a electron donor group, in the portion of the original aldehyde is crucial for biological activity. Compounds $\mathbf{2}$ and $\mathbf{3}$ had the same $\mathrm{MIC}_{90}$ value $\left(1.56 \mu \mathrm{g} \mathrm{mL}^{-1}\right)$ and have substituent such as a methoxy group and a hydroxyl in positions 4 - and 2 - in the portion of the original aldehyde, both are electron donating groups. These compounds were the second most active of the series.

Compound 1 was the third most active of the series $\left(\mathrm{MIC}_{90}=3.13 \mu \mathrm{g} \mathrm{mL}^{-1}\right)$ and differs from the others by having a substituent with electron withdrawing character of the $\mathrm{NO}_{2}$ group, as can be seen in a negative influence biological activity.

Absence of any substituent in the aromatic portion of the original aldehyde also negatively influence the biological activity of resveratrol analogs described herein, as exemplified by compound $\mathbf{5}$. This showed a $\mathrm{MIC}_{90}$ value of $6.25 \mu \mathrm{g} \mathrm{mL}^{-1}$ thus, being less active than analogue with electron withdrawing groups (1). Finally, compound $\mathbf{6}$ did not show activity against $M$. tuberculosis $\left(\mathrm{MIC}_{90}>25 \mu \mathrm{g} \mathrm{mL}^{-1}\right)$. Structurally, this analog differs from others by having three substituents methoxy group (at positions 3, 4 and 5) in the portion of the original aldehyde. It follows that besides the electron donor character of the substituent influence is still present in the number of substituents.

\section{Leishmanicidal}

Regarding antipromastigote activity, the presence of an electron donor group, in the portion of the original aldehyde, as well as the non-replacement of ring positions are favorable for leishmanicidal activity, once the compounds 2, 3, $\mathbf{4}$ and $\mathbf{5}$ showed similar activities. Thus, analogues $\mathbf{2}$ and $\mathbf{3}$ were the best, since the first showed the best activity against two of the three Leishmania species and the analogue 3 was the unique active against all Leishmania species tested (Table 3). Analogue $\mathbf{6}$ showed the second best activity against $L$. amazonensis, this result suggests that the number of substitutes does not have negative influence on biological activity. The presence of electron withdrawing group like $-\mathrm{NO}_{2}$ at para-position decreases the reactivity, whereas the analogous $\mathbf{1}$ had the lowest activity.

With respect to antiamastigote activity, similar to the observed against promastigote forms, the presence of a substituent with electron withdrawing character (analogue 1) was unfavorable to leishmanicidal activity, since this compound did not show effect against amastigotes of L. amazonensis until the highest concentration tested $\left(12.0 \mu \mathrm{gL}^{-1}\right)$. Presence of an electron donor group in the portion of the original aldehyde (analogues 2-4) induced an antiamastigote activity, characterized by similar $\mathrm{IC}_{50}$ values (Table 3). In the other hand, the non-replacement of ring positions in the compound $\mathbf{5}$, as well as the number of substituents in the compound $\mathbf{6}$, have positive influence at biological activity, once that this analogues showed the best activities against intracellular amastigotes $\left(\mathrm{IC}_{50}\right.$ of 5.93 and $5.73 \mu \mathrm{g} \mathrm{mL}^{-1}$ to the compounds $\mathbf{5}$ and $\mathbf{6}$, respectively).

\section{Conclusions}

Synthesis of new Schiff bases as resveratrol analogues was achieved in very high yield. Six regioisomers 1-6 enhanced the anti-MTB activity, having lower MICs than some drugs commonly used to treat TB. For antileishmanial assay, in general the regioisomers demonstrated a significant activity against Leishmania. Furthermore, the resveratrol analogues showed no significant cytotoxicity against mammalian cells.

\section{Supplementary Information}

Supplementary data ( ${ }^{1} \mathrm{H}$ and ${ }^{3} \mathrm{C}$ NMR and FTIR spectra) are available free of charge at http://jbcs.sbq.org.br as PDF file. 


\section{Acknowledgments}

This research was supported by CNPq, CAPES, FAPEMIG, PROPESQ/UFJF and São Paulo State Foundation (FAPESP) (grant No. 2013/14957-5). Authors thank the fellowship by CNPq (E. S. Coimbra and A. D. da Silva) and CAPES (P. A. Machado). Leishmania amazonensis (WHOM/BR/75/Josefa) transfected with GFP was generously donated by Prof Bartira Rossi-Bergmann (Federal University of Rio de Janeiro, Brazil).

\section{References}

1. World Health Organization (WHO); The Global Plan to Stop TB 2011-2015; Stop TB Partnership, 2006.

2. World Health Organization (WHO); Global Tuberculosis Report 2015; World Health Organization, 2015. http://apps.who.int/iris/ bitstream/10665/191102/1/9789241565059_eng.pdf, accessed in March 2016.

3. Gandhi, N. R.; Nunn, P.; Dheda, K.; Schaaf, H. S.; Zignol, M.; van Soolingen, D.; Jensen, P.; Bayona, J.; Lancet 2010, 375, 1830.

4. http://www.who.int/topics/leishmaniasis/en/, accessed in March 2016.

5. Alvar, J.; Velez, I. D.; Bern, C.; Herrero, M.; Desjeux, P.; Cano, J.; Jannin, J.; den Boer, M.; PLoS One 2012, 35671.

6. Torres, P.; Poveda, A.; Barbero, J. J.; Ballesteros, A.; Plou, F. J.; J. Agric. Food Chem. 2010, 58, 807.

7. Ortuño, M. A. A.; Gascón, M. A. J. Y.; Pallarés, F. J.; Vallejo, F.; Larrosa, M.; Conesa, M. A. T. G.; Barberán, F. T.; Espín, J. C.; J. Agric. Food Chem. 2010, 58, 11165.

8. Baur, J. A.; Sinclair, D. A.; Nat. Rev. Drug Discovery 2006, 5 , 493.

9. Park, E. J.; Min, H. Y.; Ahn, Y. H.; Bae, C. M.; Pyee, J. H.; Lee, S. K.; Bioorg. Med. Chem. Lett. 2004, 14, 5895.

10. Lion, C. J.; Matthews, C. S.; Stevens, M. F. G.; Westwell, A. D.; J. Med. Chem. 2005, 48, 1292.

11. Jang, L. C. M.; Udeani, G. O.; Slowing, K. V.; Thomas, C. F.; Beecher, C. W. W.; Fong, H. H. S.; Farnsworth, N. R.; Kinghorn, A. D.; Mehta, R. G.; Moon, R. C.; Pezzuto, J. M.; Science 1997, $275,218$.

12. Roberti, M.; Pizzirani, D.; Recanatini, M.; Simoni, D.; Grimaudo, S.; Abbadessa, C. D. V.; Gebbia, N.; Tolomeo, M.; J. Med. Chem. 2006, 49, 3012.

13. Renaud, S.; de Lorgeril, M.; Lancet 1992, 339, 1523.

14. Velder, J.; Ritter, S.; Lex, J.; Schmalz, H. G.; Synthesis 2006, 2006, 273.

15. Botella, L.; Nájera, C.; Tetrahedron 2004, 60, 5563.

16. Gupta, Y. K.; Chaudhary, G.; Srivastava, A. K.; Pharmacology 2002, 65, 170
17. Chao, J.; Li, H.; Cheng, K. W.; Yu, M. S.; Chang, R. C. C.; Wang, M.; J. Nutr. Biochem. 2010, 21, 482.

18. Kim, J.; Lee, H. J.; Lee, K. W.; J. Neurochem. 2010, 112, 1415.

19. Anekonda, T. S.; Brain Res. Rev. 2006, 52, 316.

20. Polonini, H. C.; Lima, L. L.; Gonçalves, K. M.; do Carmo, A. M. R.; da Silva, A. D.; Raposo, N. R. B.; Bioorg. Med. Chem. 2013, 21, 964.

21. Pavan, F. R.; de Carvalho, G. S. G.; da Silva, A. D.; Leite, C. Q. F.; Sci. World J. 2011, 26, 1113.

22. de Paula, D. T. S.; de Carvalho, G. S. G.; Almeida, A. C.; Lourenço, M.; da Silva, A. D.; Coimbra, E. S.; Mediterr. J. Chem. 2013, 2, 493.

23. Singleton, F. G.; Pollard, C. B.; J. Am. Chem. Soc. 1940, 62, 2288.

24. Manrao, C. K. M. R.; Sharma, R. C.; Kalsi, P. S.; Kaul, V. K.; Asian J. Chem. 1995, 7, 27.

25. Mobinikhaledi, A.; Steel, P. J.; Polson, M.; Synth. React. Inorg., Met.-Org., Nano-Met. Chem. 2009, 39, 189.

26. Lu, J.; Li, C.; Chai, Y. F.; Yang, D. Y.; Sun, C. R.; Bioorg. Med. Chem. Lett. 2012, 22, 5744.

27. Lima, L. L.; Lima, R. M.; da Silva, A. F.; do Carmo, A. M. R.; da Silva, A. D.; Raposo, N. R. B.; Sci. World J. 2013, 2013, 7.

28. Palomino, J. C.; Martin, A.; Camacho, M.; Guerra, H.; Swings, J.; Portaels, F.; Antimicrob. Agents Chemother. 2002, 46, 2720.

29. Pavan, F. R.; Maia, P. I. S.; Leite, S. R. A.; Deflon, V. M.; Batista, A. A.; Sato, D. N.; Franzblau, S. G.; Leite, C. Q. F.; Eur. J. Med. Chem. 2010, 45, 1898.

30. Garcia, A. V.; Clarke, R. C.; Rahn, K.; Durette, A.; MacLeod, D. L.; Gyles, C. L.; Appl. Environ. Microbiol. 1993, 59, 1981.

31. Machado, P. A.; Hilario, F. F.; Carvalho, L. O.; Silveira, M. L.; Alves, R. B.; Freitas, R. P.; Coimbra, E. S.; Chem. Biol. Drug Des. 2012, 80, 745.

32. Orme, I.; Tuberculosis Drug Screening Program; Antimicrob. Agents Chemother. 2001, 45, 1943.

33. Mosmann, T.; J. Immunol. Methods 1983, 65, 55.

34. dos Santos, A. R.; Falcão, C. A. B.; Muzitano, M. F.; Kaiser, C. R.; Bergmann, B. R.; Férézou, J. P.; Bioorg. Med. Chem. 2009, 17, 496.

35. Antinarelli, L. M.; Dias, R. M.; Souza, I. O.; Lima, W. P.; Gameiro, J.; da Silva, A. D.; Coimbra, E. S.; Chem. Biol. Drug Des. 2015, 86, 704.

36. dos Santos, E. R.; Mondelli, M. A.; Pozzi, L. V.; Corrêa, R. S.; de Araújo, H. S. S.; Pavan, F. R.; Leite, C. Q. F.; Ellena, J.; Malta, V. R. S.; Machado, S. P.; Batista, A. A.; Polyhedron 2013, 51, 292.

37. McConville, M. J.; Naderer, T.; Annu. Rev. Microbiol. 2011, 65, 543.

38. Ready, P. D.; J. Clin. Epidem. 2014, 6, 147.

39. Tempone, A. G.; de Oliveira, C. M.; Berlinck, R. G.; Planta Med. 2011, 77, 572. 
40. Rocha, M. N.; Correa, C. M.; Melo, M. N.; Beverley, S. M.; Filho, O. A. M.; Madureira, A. P.; Soares, R. P.; Diagn. Microbiol. Infect. Dis. 2013, 75, 282.

41. Ferreira, C.; Soares, D. C.; Nascimento, M. T. C.; Pinto-daSilva, L. H.; Sarzedas, C. G.; Tinoco, L. W.; Saraiva, E. M.; Antimicrob. Agents Chemother. 2014, 58, 6197.
42. Passos, C. L. A.; Ferreira, C.; Soares, D. C.; Saraiva, E. M.; PlosOne 2015, 10, e0141778.

Submitted: February 26, 2016 Published online: April 7, 2016

FAPESP has sponsored the publication of this article. 